\title{
TERCEIRIZAÇÃO: \\ implicações nas práticas de gestão de pessoas da empresa contratada
}

\section{1- Pedro Vinícius de Oliveira Carneiro Leão*}

Mestre em Administração pela Pontifícia Universidade Católica de Minas Gerais (PPGA/PUC Minas), Brasil. pedrovocl@yahoo.com.br

http://lattes.cnpq.br/7496496912124019

\section{2- Simone Costa Nunes}

Doutora em Administração pela Universidade Federal de Minas Gerais (UFMG), Brasil.

Professora do Programa de Pós-graduação em Administração da Pontifícia Universidade Católica de Minas Gerais

(PPGA/PUC Minas), Brasil.

sinunes@pucminas.br

http://lattes.cnpq.br/3716255889958071

\section{3- Antônio Carvalho Neto}

Doutor em Administração pela Universidade Federal de Minas Gerais (UFMG), Brasil.

Professor do Programa de Pós-graduação em Administração da Pontifícia Universidade Católica de Minas Gerais (PPGA/PUC Minas), Brasil.

carvalhoneto@pucminas.br

http://lattes.cnpq.br/2169195614253730

\section{4- Marcus Vinícius Gonçalves da Cruz}

Doutor em Administração pela Universidade Federal de Minas Gerais (UFMG), Brasil.

Professor do Curso de Mestrado em Administração Pública da Escola de Governo da Fundação João Pinheiro (FJP/MG), Brasil.

marcus.cruz@fjp.mg.gov.br

http://lattes.cnpq.br/3678172153181366

Diego Maganhotto Coraiola - Editor Geral

Editor responsável pela submissão:

Diego M. Coraiola.

Artigo analisado via processo de revisão duplo cego (Double-blind).

Recebido em: 12/12/2013

Aprovado em: 14/04/2014

Última Alteração: 28/03/2014

* Contato Principal: Avenida Itaú, 525. Dom Cabral, Belo Horizonte - MG, Brasil. CEP: 30535-012. 


\title{
TERCEIRIZAÇÃO: IMPLICAÇÕES NAS PRÁTICAS DE GESTÃO DE PESSOAS DA EMPRESA CONTRATADA
}

\section{RESUMO}

O objetivo do estudo é compreender como a relação estabelecida entre Contratante e Contratada afeta as práticas de gestão de pessoas da empresa terceirizada. A pesquisa adotou o método do estudo de caso e a abordagem qualitativa. A coleta dos dados ocorreu por meio de documentos e entrevistas em três empresas: a contratante; uma terceirizada, prestadora de serviços de manutenção elétrica industrial; e uma empresa que presta serviços de consultoria. Foram entrevistados gestores e trabalhadores operacionais, além de um consultor. Para analisar os dados foi escolhido o sistema em que as categorias não foram fornecidas, resultando da classificação analógica e progressiva dos elementos, segundo propõe Bardin (2011, p.113). Os resultados apontam para uma atuação intencional, planejada e consolidada por parte da Contratante sobre a Contratada que envolve práticas de gestão de pessoas nos seguintes âmbitos: recrutamento e seleção; treinamento e desenvolvimento; saúde, segurança e meio ambiente; feedback e aspectos relativos às exigências legais trabalhistas. Como conclusão tem-se que, no ambiente estudado, a terceirização se aproxima daquela preconizada pela literatura em que é justificada pela busca de maior produtividade, qualidade e competitividade.

\section{Palavras-Chave}

Terceirização. Gestão de Pessoas. Relação contratante-terceirizada.

\section{OUTSOURCING: IMPLICATIONS ON CONTRACTOR'S HUMAN RESOURCES PRACTICES}

\begin{abstract}
This article aims to understand how the relationships between the contractor and the contractee affect human resources practices within the contractor. The research has used a qualitative approach in order to conduct the case study. Data was collected through documents and interviews with managers, blue collar workers and consulting professionals from three firms: the contractor (an industrial electric maintenance services company), the contractee as well as the consulting firm. Since the categories were not pre-established, a progressive and analogic classification of the elements was applied in order to analyze the collected data. Results show an intentional, planned and consolidated action by the contractee towards the contracted firm involving the following human resources practices: recruiting and selection; training and developing; health, security and environment; feedback and legal exigencies. The results obtained from this case are similar to other outsourcing research findings which highlight it's relevance for productivity, quality and competition.
\end{abstract}

\section{Keywords}

Outsourcing. Human Resource Management. Contractor-contractee relationship. 


\section{Introdução}

A pressão proporcionada por um mercado imprevisível, exigente e com barreiras concorrenciais cada vez menores, vem demandando desde a década de 1970 empresas ágeis, eficientes e mais competitivas. O foco na competência central e a delegação das atividades acessórias para outras empresas tornaram-se premissa em um ambiente que exige eficiência, flexibilidade e agilidade das organizações (Prahalad \& Hamel, 1990). É justamente no esforço de dotar a empresa de flexibilidade e adaptabilidade que a terceirização surge como estratégia amplamente utilizada nesse cenário (Magalhães, Carvalho, \& Gonçalves, 2010).

Entendida como um dos reflexos da transição do padrão de acumulação fordista, para o modelo de acumulação flexível (Barbosa, 2010; Uderman, 2007), a terceirização pressiona os custos do trabalho para baixo, enquanto os sindicatos de trabalhadores não têm obtido sucesso para fazer frente a esse movimento (CutcherGershenfeld, Kochan, Ferguson, \& Barrett, 2007; Pochmann, 2011).

Nesse sentido, o uso da estratégia de terceirização no Brasil teve como foco principal a redução dos custos de produção (Borges \& Druck, 1993; Carvalho, 2001; Faria, 1994) e, em consequência, o rebaixamento das condições de trabalho. A difusão dessa terceirização ganha espaço quando demonstra como a pulverização da força de trabalho, distribuída espacialmente, restringe a organização dos trabalhadores e põe em cheque a conquista e defesa dos seus direitos (Lima, 2010). Esse processo contribuiu com a precarização generalizada das relações do trabalho, ao mesmo tempo associada, em alguns casos, a uma queda dos níveis de serviço, comprometendo, inclusive, os resultados econômicos das empresas optantes por uma terceirização baseada na redução de custos (Borges \& Druck, 1993; Druck, 2011; Hirata, 2011).

Essa relação de desequilíbrio, somada a resultados insatisfatórios afasta-se da ideia da terceirização como um inter-relacionamento estruturado, socialmente justo e financeiramente sustentável (Cardoso \& Marras, 2010). De acordo com diversos autores (Druck, 1999; Fernandes \& Carvalho, 2005a; Rachid, Bresciani, \& Gitahy, 2001; Rezende, 1997), os resultados negativos fizeram com que várias organizações abandonassem a estratégia de terceirização, enquanto outras optassem por reverter o processo e, ainda, algumas buscassem trabalhar no sentido de transformar essa estratégia em uma relação de parceria. As empresas que fizeram a opção pela relação de parceria, seja originariamente ou como uma opção de mudança na estratégia de terceirização, passaram a usufruir das possibilidades de se tornarem empresas mais dinâmicas e eficientes. Pesquisas apontam êxito em relações estabelecidas entre contratantes e contratadas, nas quais grandes empresas estabeleceram um relacionamento tutelar com suas contratadas, contribuindo com o seu desenvolvimento, com o aprimoramento dos serviços e produtos ofertados e com uma gestão mais eficiente da mão de obra (Gitahy, 1994; Ruas, Gitahy, Rabelo, \& Antunes, 1994; Posthuma, 1990).

Dessa forma, o enfrentamento dos maiores desafios impostos pelo ambiente da terceirização, seja na superação e distanciamento da precarização das relações de trabalho, seja no desenvolvimento e capacitação dos terceirizados, implica numa mudança das organizações em termos de gestão estratégica de seus recursos humanos (RH) (Bitencourt, 2010; Cruz, Sarsur e Amorim, 2012). Diante dessa percepção, a gestão de pessoas (GP) passa a se relacionar de forma estratégica com o ambiente organizacional, e consequentemente, da terceirização tomando para si parte do desafio de gerar resultado a partir das relações entre as organizações.

É nesse cenário, em que a gestão de pessoas da contratante alcança os processos que envolvem a contratada, com enfrentamento dos desafios da inter-relação entre essas empresas, que se estabelece a presente pesquisa. Como objetivo geral do estudo tem-se: compreender como a relação estabelecida entre Contratante e Terceirizada afeta as práticas de gestão de pessoas da empresa contratada, por meio de estudo qualitativo realizado em uma organização do ramo cimenteiro que atua no Brasil.

Além desta introdução, o artigo encontra-se estruturado em mais quatro seções. A seção 2 apresenta o referencial teórico do estudo, a seção 3 consta dos procedimentos metodológicos, a seção 4 é composta pela apresentação e análise dos dados e a seção 5 apresenta considerações finais sobre o estudo. 
Pedro Vinícius de Oliveira Carneiro Leão, Simone Costa Nunes, Antônio Carvalho Neto, Marcus Vinícius

\section{Referencial Teórico}

O uso da terceirização como estratégia nas organizações intensificou-se como parte da reestruturação produtiva, iniciada na década de 1970, quando empresas norte-americanas foram levadas a buscar novos mercados fora das fronteiras do seu país. Com o acirramento da concorrência global as empresas passaram a racionalizar suas técnicas de produção e a redesenhar sua estrutura organizacional, buscando maior capacidade competitiva (Sabel \& Zeitlin, 1985; Uderman, 2007).

No redesenho das estruturas organizacionais, a terceirização se disseminou como forma de reduzir custos, alcançar maior agilidade e flexibilidade administrativa, proporcionar a concentração na atividade principal e a transferência de parte da gestão da força de trabalho para terceiros (Borges \& Druck, 1993; Carvalho, 2001; Kolko, 1988; Olsen \& Kalleberg, 2004; Purcell, \& Purcell, 1998; Druck, 2011).

No Brasil, o processo de reestruturação produtiva apresentou-se de maneira mais efetiva a partir dos anos 1990 (Ryngelblum, 1999). As empresas brasileiras, de forma a alcançarem patamares de produtividade que garantissem maior competitividade, passaram a buscar uma progressiva flexibilização das suas estruturas de produção, adaptando-as à necessidade de se tornarem cada vez mais ágeis nas mudanças e mais competentes no desenvolvimento dos seus negócios. Intensificou-se, então, a contratação de empresas prestadoras de serviços e a concentração das empresas centrais em suas atividades principais (Sarsur, Cançado, Fernandes, \& Steuer, 2002).

Sob um olhar estritamente empresarial, a existência de um modelo de produção mais flexível, que se molda às contingências dinâmicas da nova realidade, agrega mais benefícios ao processo produtivo do que malefícios. Mas, o êxito na flexibilidade pretendida depende, conforme argumentam Izquierdo e Cillán (2004), de altos níveis de cooperação, planejamento em conjunto e adaptação mútua às necessidades das partes envolvidas. Segundo Marchalek, Rebelato e Rodrigues (2007), ameaças presentes no contexto organizacional e vivenciadas pelas empresas no decorrer do processo de reestruturação produtiva acabaram por submeter o relacionamento entre contratantes e contratadas a uma lógica de integração que vai além da troca física de bens e avança sobre o campo do conhecimento, informação, $P \& D$, entre outros.

Marchalek et al. (2007) acrescentam que a troca de informações entre as empresas deve contemplar questões técnicas e estratégicas de forma a facilitar a tomada de decisões, o planejamento compartilhado e a solução conjunta de problemas, reduzindo as incertezas e aumentando o controle. A comunicação aberta entre a contratante e as suas contratadas contribui para o desenvolvimento de interações e fortalece os laços de confiança que embasam os relacionamentos cooperativos. Entretanto, essa percepção empresarial mostra-se antagônica quando esse mesmo modelo é visto sob o ponto de vista das relações de trabalho (Barbosa, 2010), tema discutido na sequência deste artigo.

\subsection{O Impacto da Terceirização nas Relações de Trabalho}

Frente aos desafios da terceirização, como salientam Almeida e Silva (1999), se a estratégia de terceirização não for implantada de forma organizada e estruturada para uma relação de parceria, pode provocar reações adversas para todas as empresas envolvidas, gerando níveis indesejados de conflitos com os trabalhadores e seus sindicatos, sem melhores resultados para as partes.

Sob a perspectiva do trabalhador, a literatura dominante trata da associação entre a terceirização e outras inovações organizacionais que vieram na esteira da reestruturação produtiva das grandes empresas e que trouxeram, entre outros, maior precarização das relações de trabalho, diminuição de direitos conquistados e enfraquecimento dos sindicatos de classe (CutcherGershenfeld et al., 2007; Cruz et al., 2012; Saraiva, Ferreira, \& Coimbra, 2012).

A terceirização, por si só, trouxe um aumento significativo de trabalhadores com múltiplos vínculos contratuais, o pagamento de salários abaixo da média do mercado e o estabelecimento de relações informais de trabalho, entre outros. Nesse contexto, organizações passaram a contar com três principais tipos de vínculos com seus trabalhadores: o tradicional, com carteira de trabalho assinada e demais garantias legais; o temporário, com objetivo de suprir necessidades extraordinárias, ocasionais ou inesperadas; e o decorrente da terceirização (Magalhães et al., 2010; Druck, 2011). 
Como pontua Barbosa (2010), a precariedade trazida pelo processo de flexibilização das relações de trabalho no caso brasileiro representou uma perda gradativa da hegemonia do contrato de trabalho por tempo indeterminado. Isso afeta um dos princípios balizadores do Direito do Trabalho, o da continuidade da relação de emprego, afetando também a organização sindical coletiva dos trabalhadores, antes focada quase que exclusivamente na representação dos trabalhadores submetidos a contrato por tempo indeterminado. Essa quebra da proteção do emprego por prazo indeterminado tornou mais distante do empregado o sentimento de estabilidade, definindo novos conjuntos de trabalhadores caracterizados em três grandes grupos: os proletários estáveis e com garantias; os excluídos do trabalho, condenados ao desemprego e à dependência de programas sociais do governo; e os trabalhadores instáveis, submetidos a vínculos por tempo parcial, temporários, informais e terceirizados.

Também na análise do conjunto de trabalhadores envolvidos em um ambiente de terceirização, Figueiredo, Alvarez, Athayde, Suarez e Pereira (2007) descrevem a importância dos coletivos de trabalho, em menores proporções, como um grupo ou equipe de trabalho ou, em maiores proporções, como as representações sindicais dos trabalhadores, que pressupõem regras e leis próprias que ajudam a organizar as relações entre as pessoas. O resultado é a coesão do grupo, que se vê protegido de ameaças externas, além de garantir um maior potencial de cooperação entre seus participantes. A instabilidade das relações de emprego e a multiplicidade de vínculos que refletem diversas identidades aos trabalhadores indiretos desarticulam o coletivo de trabalho e os distanciam ainda mais dos trabalhadores diretos, formalmente contratados pelas empresas centrais. Dessa forma, vários autores (Guimarães \& Carvalho, 2006; Barbosa, 2010) apontam a terceirização como um dos mais importantes fatores de intensificação do processo de fragmentação da classe trabalhadora, desconstruindo o sindicalismo classista tal como se configurou durante o fordismo, bem como a rede de proteção social que caracterizou aquele período.

De forma geral, as empresas brasileiras transferiram para as empresas contratadas o ônus de boa parte das suas atividades e, principalmente, das suas expectativas em relação a custos, produtividade e qualidade. Sob essa demanda, as terceiras passam a vivenciar um processo repleto de contradições, uma vez que são pressionadas a produzirem mais, em menos tempo, a um preço cada vez menor e com uma qualidade cada vez maior. Almeida e Silva (1999) argumentam que o foco em diminuição de custos pode ser benéfico a curto prazo, entretanto, a longo prazo, o atendimento às exigências quanto à qualidade e a questões técnico-econômicas e jurídicas, pode gerar prejuízos, seja em relação à conformidade do produto/serviço, a questões trabalhistas ou a aspectos do clima interno e das relações de trabalho.

Queiroz (1998) argumenta que terceirizar não é difícil, porém, nem sempre é fácil garantir a eficiência em serviços delegados a terceiros. Na maioria das vezes, é necessário agir como parceiro, o que requer esforço da contratante e tempo de adaptação da contratada. Nesse sentido, Rezende (1997) afirma que, quando implementada dentro de critérios consistentes, a terceirização traz resultados positivos como a melhoria da competitividade, o aumento do lucro, uma grande ampliação da flexibilidade técnica e econômica, a redução da burocracia e a possibilidade concreta de estabelecimento de parcerias entre empresas. Tais argumentos são também aderentes o estudo de Saraiva e Mercês (2013, p.21), no qual a parceria é destacada como um conceito que viabiliza a terceirização enquanto "especialização produtiva associada a benefícios compartilhados."

Rachid et al. (2001) afirmam que a ligação das pequenas e médias empresas fornecedoras com as grandes empresas clientes, em especial com as pertencentes à indústria automobilística, tem resultado num processo de qualificação dos fornecedores que passam a ter acesso a informações sobre as práticas mais atuais de gestão. A busca por uma terceirização que promova ganhos mútuos, passa pela capacitação das empresas envolvidas no processo. Segundo Fernandes (2003), preparar as organizações e os líderes para uma melhor gestão de pessoas com seus múltiplos vínculos de trabalho, reduzindo os efeitos negativos da flexibilização, passa a ser um dos grandes desafios da gestão.

\subsection{A Gestão de Pessoas no Contexto da Terceirização}

Salerno (2004) aponta que a disseminação das mudanças propostas a partir do processo de reestruturação produtiva enfrentou obstáculos decorrentes de particularidades das relações de trabalho no Brasil. Entre elas, a discrepância de tratamento entre core workers e terceirizados, em termos de remuneração, benefícios e condições de trabalho (Carvalho, 2001; Magalhães, 2008). Além disso, diversos autores discutem o impacto negativo no trabalho das equipes formadas por diferentes vínculos contratuais e a precarização das relações de trabalho decorrentes da 
Pedro Vinícius de Oliveira Carneiro Leão, Simone Costa Nunes, Antônio Carvalho Neto, Marcus Vinícius

terceirização (Dedecca, 1996; Hall, 2000; Sarsur et al., 2002; Fernandes \& Carvalho, 2005a, b; Saraiva et al., 2012).

Magalhães et al. (2010) ressaltam que os trabalhadores terceirizados tendem a ser alvo de tratamento preconceituoso, consequência de uma concepção estereotipada que os qualifica como possuindo baixo conhecimento, pouca qualificação, pouca ética no trabalho e que são inferiores em relação aos trabalhadores das contratantes. Para Barbosa (2010), a todos esses fatores soma-se o distanciamento do sentimento de estabilidade que conduziria a uma inserção social por meio do trabalho.

Para fazer frente a esse contexto de novas configurações organizacionais e da flexibilização das relações de trabalho, a gestão de pessoas adquire maior complexidade, representando um grande desafio para as empresas (Silva, Cançado, Fernandes, \& Steuer 2001; Bitencourt, 2010; Cruz et al., 2012) e para a própria área de recursos humanos (Kochan, 1997, 2006). Na medida em que o ambiente ganhou maior nível de complexidade, também se tornaram mais complexas as estratégias de gestão de recursos humanos.

O modelo burocrático de gestão de pessoas, orientado para o controle, vem migrando para um modelo mais flexível e capaz de responder às situações que se apresentam complexas, instáveis e inesperadas (Fernandes \& Carvalho, 2005a) e que requerem o manejo das contradições e diversidades de forma a combinar interesses conflitantes e obter benefícios sustentáveis da flexibilização do trabalho. (Fernandes, 2003).

Nesse sentido, o papel a ser desempenhado pela gestão de pessoas passa a ser o de repensar as atividades próprias da área de $\mathrm{RH}$ em termos estratégicos, ou seja, de forma a integrar os objetivos de longo prazo da organização, as variáveis relevantes do ambiente e as necessidades decorrentes em termos de pessoas (Lacombe \& Tonelli, 2001; Bitencourt, 2010; Cruz et al., 2012).

Não obstante, Fernandes e Carvalho (2005a) argumentam que, se, de um lado, novas formas de gerir a força de trabalho tornam-se cada vez mais necessárias, de outro lado, os resultados de pesquisas sugerem a existência de hiato entre essas práticas e aquelas efetivamente adotadas pelas empresas brasileiras frente aos desafios da gestão de terceirizados: contar com uma equipe qualificada de terceirizados; assegurar a melhoria da qualidade de serviços; garantir que os serviços contratados sejam padronizados; e obter comprometimento dos terceirizados. (Fernandes \& Carvalho, 2005a).

No que diz respeito a esses desafios citados por Fernandes e Carvalho (2005a), Magalhães, Carvalho e Saraiva (2011) afirmam que o tema qualificação é, ainda, alheio aos contratos de prestação de serviços que se restringem, em regra, ao objeto do contrato, ao seu valor, aos seus prazos, às formas de controle e às obrigações das partes envolvidas. Dessa forma, a responsabilidade pela condução de processos de qualificação e comprometimento dos trabalhadores recai sobre os gestores que precisam propiciar ambiente e recursos de trabalho que sejam favoráveis aos profissionais com diferentes tipos de vínculos contratuais.

Embora ainda pareçam tímidas as iniciativas das organizações brasileiras no tocante à gestão dos terceirizados conforme discutem Fernandes e Carvalho (2005a) há exemplos que denotam a preocupação em lidar com os desafios colocados pelo ambiente da terceirização, entre eles: as empresas têm investido na definição de critérios, políticas e regras para orientarem a gestão do contrato de terceiros; a contratante passa a orientar os processos de seleção dos terceirizados por meio da contratação e negociação de metas e pelo acompanhamento e avaliação do desempenho; os terceiros são integrados aos processos de treinamento e desenvolvimento da contratante com vistas a lidar com a questão da capacitação de trabalhadores terceiros; a avaliação de metas, a supervisão e o feedback passam a ter como objetivo a garantia de melhoria dos serviços; os terceiros são envolvidos no planejamento de trabalho e na troca de experiências; e processos estruturados de certificação para as empresas terceirizadas são estabelecidos (Fernandes \& Carvalho, 2005a).

$\mathrm{Na}$ mesma direção, outros estudos apontam resultados que indicam políticas e práticas adotadas pelas organizações visando romper com os obstáculos no contexto da relação contratanteterceirizada, a exemplo dos estudos de Lourenço, Villela e Freitas (2010) e de Lisboa, Carvalho, Nunes e Lima (2011).

A pesquisa realizada por Lourenço, Villela e Freitas (2010) mostra que a empresa contratante busca regular a gestão de pessoas das terceirizadas por meio do estabelecimento de políticas de recursos humanos que são adotadas pelas empresas presentes em sua rede. Entre os resultados 
apontados encontra-se a influência positiva sobre a produtividade laboral decorrente da geração de um ambiente sadio e motivador. As políticas enfatizadas são: avaliação de desempenho, considerada como justa; programas de treinamento comportamental voltados à melhoria nas relações entre colegas e com os supervisores; ênfase na troca de conhecimentos com colegas, o que contribui para desenvolver competências profissionais; salários e benefícios alinhados com o mercado. (Lourenço et al., 2010, p.55).

O trabalho de Lisboa et al. (2011, p.2), realizado em empresas contratadas do segmento logístico de distribuição, argumenta que há evolução consistente no relacionamento entre contratadas e seus empregados, "principalmente em questões como a formalização das relações de trabalho, as políticas de remuneração, os benefícios e as oportunidades de reconhecimento e valorização profissional."

Não obstante, o quadro desafiador parece persistir. Sob a perspectiva de Cardoso e Marras (2010), é preciso desenvolver vários tipos de relações colaborativas entre as empresas, ampliando as suas fronteiras, construindo sistemas que coexistam com novas culturas e orientem as pessoas para a criação e manutenção constante de vantagens competitivas. Fernandes e Carvalho (2005a, p.14) acrescentam que "será necessário estabelecer mecanismos que promovam participação, troca, aprendizagem mútua e contínua, poder de decisão e autonomia dos terceirizados. Isto demanda, por sua vez, um maior grau de confiança nas relações."

\section{Procedimentos Metodológicos}

O método utilizado nesta pesquisa é o estudo de caso de natureza qualitativa que se mostrou adequado para conhecer o fenômeno da terceirização uma vez que este é resultado da interação de diversas variáveis que podem ser interpretadas de maneiras igualmente diversas pelos atores que se pretende estudar (Collis \& Hussey, 2005): contratante e contratada. Para a seleção das unidades de análise foram considerados dois critérios básicos:

a) a inserção das empresas no contexto da terceirização, com outras experiências vividas como tomadora de serviços (contratante) ou prestadora (contratada);

b) a existência de um relacionamento contratual de mais de cinco anos entre a contratante e a contratada.

Esse último critério foi considerado relevante tendo em vista a consolidação do relacionamento entre as empresas e a possível evidenciação de um processo em que a atuação da Contratante afeta a Contratada, nesse caso, em suas práticas de gestão de pessoas. Além das duas empresas escolhidas - Contratante e Contratada - o estudo envolveu uma empresa de Consultoria que se encontrava a serviço da Contratante à época da realização da pesquisa. A opção de inserir a empresa de Consultoria tornou-se mandatória durante os procedimentos de levantamento de dados uma vez que, apesar de não estar prevista inicialmente, esta organização é responsável pela regulação de algumas das principais relações entre a contratante e terceirizada ao longo do período contratual de prestação de serviços.

Optou-se por utilizar nomes fictícios para a Contratante (Cimenteira) e para a Contratada (Terceirizada).

A Figura 1 apresenta uma breve caracterização das empresas investigadas:

\begin{tabular}{l|l}
\hline \multicolumn{1}{c|}{ Empresa } & \multicolumn{1}{c}{ Perfil } \\
\hline $\begin{array}{l}\text { Contratante } \\
\text { (Cimenteira) }\end{array}$ & $\begin{array}{l}\text { A organização contratante é do ramo cimenteiro, multinacional de capital privado, atuando } \\
\text { no país desde 1968, sendo uma das cinco maiores de seu setor. Conta em seus quadros com } \\
\text { aproximadamente 2 mil empregados diretos e outros 3 mil terceirizados. }\end{array}$ \\
\hline $\begin{array}{l}\text { Contratada } \\
\text { (Terceirizada) }\end{array}$ & $\begin{array}{l}\text { A Terceirizada, também de capital privado, atua no segmento de manutenção elétrica } \\
\text { industrial. Essa empresa está em atividade no mercado desde 1997 e presta serviços à } \\
\text { Cimenteira há cerca de seis anos. Atualmente, conta com 45 empregados, sendo 18 deles } \\
\text { atuantes na prestação de serviços à Cimenteira. }\end{array}$ \\
\hline Consultoria & $\begin{array}{l}\text { A organização mediadora é do ramo de consultoria, nacional de capital privado, atuando } \\
\text { desde 2008. Seu portfólio de serviços compreende o planejamento e execução de processos } \\
\text { de homologação de fornecedores, auditorias e desenvolvimento e administração de padrões } \\
\text { de gestão em redes de fornecedores. }\end{array}$ \\
\hline
\end{tabular}

Figura 1 - Perfil das empresas selecionadas

Fonte: Elaborada pelos autores. 
Sendo o objetivo geral da pesquisa a busca da compreensão de como a relação estabelecida entre Contratante e Terceirizada afeta as práticas de gestão de pessoas da empresa contratada, o estudo tem a seguinte "hipótese diretriz" (Bardin, 2011, p.61): existe um processo de atuação de empresas contratantes sobre suas contratadas que afeta as práticas de gestão de pessoas das terceirizadas. Partindo dessa definição, foram estabelecidos cinco objetivos específicos para a pesquisa:

a) verificar se a atuação da contratante sobre as práticas de gestão de pessoas da contratada é um processo claramente estabelecido e percebido;

b) identificar as práticas de gestão de pessoas sobre as quais a contratante busca exercer atuação na contratada;

c) identificar os meios utilizados pela contratante para atuar sobre a gestão de pessoas da contratada;

d) conhecer os motivos que levam a contratante a atuar sobre as práticas de gestão de pessoas da contratada e os resultados obtidos;

e) conhecer a percepção dos envolvidos quanto à aderência da contratada às orientações da contratante.

Na sequência foram definidas as dimensões que nortearam a coleta documental dos dados e a elaboração das questões dos roteiros de entrevista:

I- Orientação dada às práticas de GP;

II- Práticas de GP afetadas;

III- Meios de atuação;

IV- Motivos para atuar sobre as práticas de GP;

V- Adesão das contratadas.

A coleta de dados teve início com a análise documental na Consultoria nos termos sugeridos de Ludke e Andre (1986), voltada para identificar informações factuais nos documentos a partir das questões de intermediação entre Contratante e Terceirizada. Os serviços prestados pela Consultoria à Cimenteira contam com o auxílio de um sistema informatizado por meio do qual tramitam documentos e informações entre as três empresas: Cimenteira, Terceirizada e Consultoria. Foram analisados quatro diferentes tipos de documentos elaborados pela Consultoria juntamente com a Cimenteira, destinados à orientação, definição de regras e fiscalização das empresas contratadas. Eles são os seguintes: um manual contendo descrição e regras do relacionamento entre a Cimenteira e as contratadas; um questionário de auditoria utilizado para avaliar as contratadas; um questionário utilizado no processo de homologação de fornecedores; e um arquivo digital contendo a apresentação da Consultoria.

Após a análise dos documentos foi realizada a coleta de dados por meio de entrevistas semiestruturadas, conforme preconiza Flick (2004), uma vez que as entrevistas permitem que os pontos de vista dos entrevistados sejam expressos. Para tanto, foram utilizados quatro roteiros de entrevista, um para cada tipo de respondente: Gestores da Cimenteira, Gestores da Terceirizada, Empregados da Terceirizada e Consultor.

Participaram da pesquisa 15 pessoas assim distribuídas: Consultoria - um consultor; Cimenteira - um gestor com atuação em nível estratégico e um gestor em nível tático; Terceirizada um gestor com atuação em nível estratégico e outro em nível tático; e 10 trabalhadores pertencentes ao nível operacional. O Consultor foi entrevistado na sede da empresa de consultoria, enquanto os demais foram entrevistados nas dependências da Cimenteira.

Os gestores foram escolhidos pelo fato de atuarem diretamente no contrato existente entre a Cimenteira e a Terceirizada. Quanto aos trabalhadores operacionais, foram entrevistados 10 de um total de 18 que atuam diretamente na empresa Contratante. As participações ocorreram na medida da disponibilidade de cada um, durante o período de trabalho. Ao final da 10 a entrevista concluiu-se que os dados tinham atingido o nível de saturação, conforme aponta Gaskell (2002, p.71): “a certa altura o pesquisador se dá conta que não aparecerão novas surpresas ou percepções". Com essa premissa, percebeu-se que não seria necessário entrevistar os oito trabalhadores restantes.

Todas as entrevistas foram individuais, gravadas e transcritas. De forma a garantir o anonimato dos entrevistados, os seus nomes, cargos, funções e outras informações que pudessem 
identificá-los foram omitidos. Para fins de identificação de suas falas, foram usados códigos. O Consultor recebeu o código CS1. Os entrevistados da Cimenteira podem ser identificados como CTE1 e CTE2. Para a Terceirizada há 12 códigos iniciados com as letras TER, seguidas de números que vão de 1 a 12.

Recorreu-se à análise de conteúdo para tratar e analisar os dados. Durante o tratamento destes, verificou-se a necessidade de modificação nas dimensões traçadas a priori de forma a melhor explicitar os resultados. A cada uma das dimensões foram associadas categorias temáticas que não haviam sido previamente fornecidas, resultando da classificação analógica e progressiva dos elementos. Dessa maneira, o título conceitual de cada categoria somente foi definido no final da operação, conforme sugere Bardin (2011). A Figura 2 apresenta as dimensões e respectivas categorias:

\begin{tabular}{|c|c|}
\hline Dimensão & Categoria temática \\
\hline $\begin{array}{l}\text { Estabelecimento e } \\
\text { manutenção da relação }\end{array}$ & $\begin{array}{l}\text { - Homologação de fornecedores } \\
\text { - Enquadramento no modelo de gestão } \\
\text { - Acompanhamento e avaliação }\end{array}$ \\
\hline $\begin{array}{l}\text { Orientação e } \\
\text { monitoramento }\end{array}$ & $\begin{array}{l}\text { - Meios para orientar os terceiros } \\
\text { - Auditorias } \\
\text { - Atuação da Consultoria }\end{array}$ \\
\hline $\begin{array}{l}\text { Práticas de GP afetadas } \\
\text { na Contratada }\end{array}$ & $\begin{array}{l}\text { - Recrutamento e seleção } \\
\text { - Saúde, Segurança e Meio Ambiente } \\
\text { - Treinamento e desenvolvimento } \\
\text { - Feedback } \\
\text { - Aspectos legais das relações de trabalho }\end{array}$ \\
\hline $\begin{array}{l}\text { Motivos e resultados da } \\
\text { atuação da Contratante }\end{array}$ & $\begin{array}{l}\text { - Melhoria de qualidade e produtividade } \\
\text { - Melhoria na segurança do trabalho } \\
\text { - Qualificação de fornecedores } \\
\text { - Co-responsabilidade nas relações de trabalho } \\
\text { - Atendimento às exigências legais }\end{array}$ \\
\hline
\end{tabular}

Figura 2 - Dimensões e categorias de análise

Fonte: Elaborada pelos autores.

Na sequência deste artigo são apresentados e analisados os dados à luz da teoria.

\section{Apresentação e Análise dos Dados}

\subsection{Estabelecimento e Manutenção da Relação Contratante-Terceirizada}

O passo inicial em direção ao estabelecimento de relação entre a Cimenteira e suas contratadas para o fornecimento de produtos e serviços é dado no processo de homologação de fornecedores, que ocorre sob a responsabilidade da empresa de Consultoria. Esse processo envolve a avaliação das empresas terceiras sob diversos aspectos tais como a existência de condições degradantes como trabalho escravo e infantil; assédio moral; questões relacionadas à segurança do trabalho; e práticas adotadas relacionadas a treinamento, desenvolvimento e comunicação com os empregados.

Se aprovada no processo de homologação e inserida no quadro de fornecedores da Cimenteira, a contratada é orientada a partir de padrões previamente definidos, baseados no ordenamento jurídico-trabalhista brasileiro e no modelo de gestão estabelecido pela Cimenteira:

As empresas que adentram a fábrica passam por um trabalho de integração, onde são mostradas e divulgadas todas as práticas que a empresa prega aqui com relação a pessoas, gestão de pessoas, e também de segurança (CTE2 - gestor).

Os entrevistados, em geral, confirmaram a intenção da Cimenteira de enquadrar as contratadas em seu modelo de gestão, que revela um conteúdo padrão aplicado às empresas terceiras. O trecho da fala a seguir explicita o seu uso: "Para que o resultado do trabalho seja adequado [...] é necessário que esse terceiro tenha um mínimo de aderência ao modelo de gestão aplicado pela organização maior, que é a tomadora de serviço." (CTE1 - gestor). Não obstante, esse entrevistado disse que não existe a obrigação das terceiras em aderir ao seu modelo: "No primeiro 
momento, a empresa precisa deixar claro que o processo não é obrigatório. Eu não posso, de forma nenhuma, criar uma ingerência com qualquer empresa aqui dentro." (CTE1 - gestor).

Não obstante, ficou evidente que a adesão das contratadas ao modelo de gestão da Cimenteira é essencial para a manutenção e evolução da relação estabelecida entre as empresas. Como forma de garantir tal adesão, auditorias periódicas são realizadas pela Cimenteira com a intenção de medir o quão aderentes ao modelo de gestão encontram-se as práticas das terceirizadas.

Os padrões estabelecidos e os mecanismos de acompanhamento e avaliação dos fornecedores são rígidos, segundo os entrevistados. A partir das auditorias e das análises feitas pela Consultoria são tomadas as decisões sobre a permanência e abrangência do contrato com cada fornecedor. Assim, reforça-se que a adesão das contratadas ao modelo de gestão mostra-se condição fundamental para que a relação contratual perdure e se desenvolva. Isso pode ser atestado pela fala de outro entrevistado: "Se não atendesse, a gente não estaria trabalhando com ela." (CTE2 - gestor).

Outro aspecto que reforça a atuação da Cimenteira sobre as suas contratadas refere-se à clara política de estabelecimento de vínculos de longo prazo, garantindo a continuidade do processo. 0 desejo de manutenção da relação pode ser constatado por meio das falas dos gestores da Cimenteira e também é claramente divulgado nos materiais corporativos da empresa, conforme relataram representantes da Terceirizada.

Pode-se verificar que a atuação da Cimenteira sobre as suas contratadas tem proximidade com aquilo que foi adotado pela empresa estudada por Magalhães et al. (2010) e também pela contratante pesquisada por Lourenço et al. (2010). O primeiro estudo constatou que a mineradora atua sobre as terceirizadas por meio do estabelecimento de padrões, normas e procedimentos a serem seguidos. Práticas relacionadas a treinamento e desenvolvimento são exemplos da atuação dessa empresa sobre as suas contratadas (Magalhães et al., 2010). O segundo trabalho verificou que a empresa contratante induz as suas prestadoras de serviços a adotarem políticas formais de recursos humanos quanto a: avaliação de desempenho, programas de desenvolvimento, compartilhamento de conhecimentos entre os trabalhadores e programa de remuneração consistente com o mercado (Lourenço et al., 2010).

\subsection{Orientação e Monitoramento: a Aderência da Terceirizada ao Modelo de Gestão da Cimenteira}

As orientações da Cimenteira são passadas diretamente por seus representantes para o nível operacional da Terceirizada ou, então, para os representantes do nível tático e/ou estratégico, que as repassam aos demais. Diante disso, faz-se necessário esclarecer que o contato direto da Cimenteira com operários da Terceirizada é inevitável, mas, não é capaz de estabelecer, por si só, uma relação de subordinação. Reservado o viés de controle e monitoramento para o trato corporativo entre a Cimenteira e as suas contratadas, pautado pela relação contratual existente, o diálogo meramente informativo mantido com os empregados da Terceirizada não se associa à subordinação, importante elemento componente da relação de emprego. Contudo, essa distinção exige cuidado e habilidade por parte da Cimenteira.

Reuniões entre representantes das empresas são diárias e tratam de temas operacionais, comportamentais e, sobretudo de segurança do trabalho. Fóruns e comitês de área reúnem-se semanalmente e discutem temas considerados críticos de acordo com aspectos específicos do momento e da área. Apesar das especificidades, essas reuniões não se distanciam das prioridades definidas no modelo de gestão da Cimenteira.

De acordo com os entrevistados da Cimenteira, o modelo de gestão não se destina a atender exclusivamente às necessidades voltadas às terceiras. Ele foi incorporado pela Cimenteira e guia também as suas próprias práticas. Há expectativa de criação de um ambiente em que valores são compartilhados entre Contratante-contratadas. Isso promove o compartilhamento de orientações entre empregados de ambos os lados, conforme trecho da fala a seguir:

Não há diferença nenhuma, são as mesmas ferramentas. Ou seja, o que é aplicado na [ Cimenteira], os terceiros também aplicam. E participam juntamente com os comitês na [Cimenteira], são todos juntos, não tem diferença de um comitê separado e o outro (TER3 - operacional).

As reuniões entre ambas as empresas, independente do nível organizacional, também são utilizadas para dar feedback, o que representa mais um meio utilizado pela Cimenteira para atuar sobre as práticas da Terceirizada. A convivência diária no ambiente de produção, as constatações 
feitas em auditorias e os relatórios elaborados pela Consultoria fornecem informações à Cimenteira que possibilitam que seja dado feedback detalhado à Terceirizada. De forma geral, a adesão da Contratada ao modelo de gestão é o principal conteúdo do feedback. Com isso, a Cimenteira pretende direcionar a Terceirizada para uma maior incorporação dos seus padrões de gestão.

As auditorias são realizadas pela Cimenteira semestralmente. Quando são identificadas, nas contratadas, práticas conflitantes com o modelo de gestão da Cimenteira, o monitoramento e suporte sobre a terceira se intensificam de forma a garantir sua adequação ao que é esperado, conforme dito a seguir: "A empresa que descumpre uma norma aqui dentro tem que passar por auditoria, onde que ela tem que voltar a ser eficaz. [...] Então a empresa tem que, periodicamente, fazer uma auditoria e, de novo, dar uma investigada num dos sistemas, se está dentro daquilo que é proposto." (CTE2 - gestor).

A falta de aderência da Terceirizada a determinados quesitos pode impedir o acesso de seus empregados às fábricas da Cimenteira, principalmente em termos de normas trabalhistas. O trecho da fala de um dos gestores da Cimenteira reforça a ênfase dada aos processos de monitoramento e orientação: "O que eu vou fazer para que ela tenha isso na veia, no sangue dos seus profissionais? Monitorar, acompanhar e auditar, e dar suporte, para que ela melhore o seu desempenho interno. [...] Dar suporte para que ela faça o seu processo dentro do sistema de gestão." (CTE1 - gestor).

Destaca-se que além da Cimenteira, a Consultoria também tem o papel de orientar e monitorar as contratadas. Logo, o relacionamento entre Contratante-contratadas é, muitas vezes, mediado pela Consultoria, cujo trabalho consiste em desenvolver, aplicar, treinar e monitorar padrões de regularidade. Periodicamente a Consultoria apresenta à Cimenteira relatórios gerenciais que detalham a situação de regularidade de cada uma de suas empresas terceiras frente aos padrões estabelecidos. Os resultados apurados fundamentam novas ações com a finalidade de orientar as contratadas e conduzi-las ao patamar de regularidade entendido como ideal no contexto da Cimenteira. Esse ciclo permanece no decorrer de toda a relação contratual entre as empresas.

Sobre a atuação da Consultoria, segue a fala de um entrevistado:

O nosso carro chefe na [ Cimenteira] é o programa de análise trabalhista. É um programa que orienta os fornecedores a enviarem informações e documentos para a Consultoria, que analisa e cruza informações diversas para concluir sobre os riscos oferecidos por cada fornecedor. Nós também orientamos esses fornecedores sobre como buscar a regularidade, dentro dos padrões estabelecidos (CS1 - consultor).

Em suma, a atuação da empresa Contratante sobre as suas contratadas decorre de uma clara política de relacionamento entre essas empresas, orientada por padrões próprios de gestão da Cimenteira, conforme espelha o trecho a seguir: "São várias as exigências no dia a dia e também no contrato, enfim, na prestação de serviços em geral, que fazem com que a gente siga várias orientações da [ Cimenteira]." (TER1 - gestor).

Assim como apontado pela pesquisa de Fernandes e Carvalho (2005a), a avaliação de metas, a supervisão, o feedback, além do estabelecimento de processos estruturados de certificação para as empresas terceirizadas alinham-se aos mecanismos de controle e orientação estabelecidos pela Cimenteira em conjunto com a empresa de Consultoria.

\subsection{Práticas de Gestão de Pessoas da Terceirizada Afetadas pela Cimenteira}

O modelo de gestão da Cimenteira abarca diversos aspectos sendo que aqueles que se relacionam à gestão de pessoas estão incluídos nos temas a seguir, em especial: equipe técnica da empresa terceira; procedimentos e normas; requisitos legais; definição de objetivos e metas; execução dos planos; treinamento; controle de documentos; ferramentas; e verificação dos resultados. Dos 53 quesitos que se relacionam a esses temas quase a metade diz respeito à SSMA 26 itens. Os 27 itens restantes demonstram preocupações da Cimenteira com relação a comunicação, feedback e adequação legal da empresa terceira às leis trabalhistas. Associado a isso, a empresa faz exigências quanto à manutenção de pessoal treinado e alinhado às suas expectativas de qualidade e produtividade.

Os entrevistados da Cimenteira relataram que há preocupação com as diferenças culturais trazidas por empregados de suas contratadas, pois o conflito de valores leva ao aumento na rotatividade dos terceirizados. Como resultado, verifica-se na Terceirizada que os processos de recrutamento e seleção consideram a contratação de trabalhadores adequados ao perfil da 
Pedro Vinícius de Oliveira Carneiro Leão, Simone Costa Nunes, Antônio Carvalho Neto, Marcus Vinícius

Cimenteira, ou seja, que se mostrem capazes de assimilar e adequar-se ao seu contexto. O trecho a seguir fornece indícios sobre isso:

Como se trata de um cliente exigente, principalmente em questões de segurança do trabalho, além da qualidade do serviço, é lógico, temos que contratar pessoas que podem absorver todo o conteúdo nosso e da [ Cimenteira]. [...] A gente, na verdade, tem que adequar todos os nossos processos de gente ao perfil do cliente (TER1 - gestor).

O pessoal terceirizado é, em certos casos, treinado pela Cimenteira, especialmente quanto ao tema SSMA. O primeiro treinamento ocorre quando inicia a prestação de serviço. Trata-se do treinamento de integração: “...passam por um trabalho de integração, onde são mostradas e divulgadas toda a prática que a empresa prega aqui com relação a pessoas, gestão de pessoas, e também de segurança (CTE2 - gestor). O trecho da fala de um dos entrevitados na Contratada confirma essa prática:

Até que a parte de segurança aqui, quando a gente vai entrar na empresa, a gente passa pela integração. Já teve alguns treinamentos também que a gente participou. E sempre falam também no DDS [ diálogo diário sobre segurança], que estão sempre informando sobre segurança. (TER3 - operacional).

Além disso, usualmente, a Cimenteira ou a Consultoria repassam às empresas contratadas as demandas por treinamento de seus empregados.

No que se refere às relações de trabalho, especialmente à gestão de risco de passivo trabalhista, a Cimenteira gerencia os impactos derivados de possíveis descumprimentos dos direitos dos empregados, a partir das ações da Consultoria. Segundo a Terceirizada, as orientações e exigências da Cimenteira, espelhadas principalmente pela Consultoria, acabam por elevar o nível de organização das empresas contratadas quanto à documentação e rotinas trabalhistas. "A gente recebe muita orientação de como fazer em relação a documentos de obrigações trabalhistas. $\mathrm{Na}$ verdade a própria lei já exige, mas como o cliente quer tudo bonitinho, com documentação em dia, temos que ter uma organização muito boa pra conseguir atender." (TER1 - gestor).

De acordo com o Consultor, a ênfase na regularidade de alguns indicadores (absenteísmo, turnover e acidentes) e também os cuidados com aspectos das relações de trabalho decorrem da percepção de que esses fatores interferem na qualidade e produtividade dos serviços prestados: "A rotatividade excessiva de empregados, salários atrasados, falta de atendimento aos direitos dos empregados de forma geral, tudo isso acaba interferindo na qualidade do serviço." (CSI - consultor).

Esse trecho da fala do Consultor permite verficar, entre outros, que a despeito de não se ter verificado ações diretas da Cimenteira sobre a definição da remuneração dos empregados das contratadas, há acompanhamento sobre a regularidade e forma com a remuneração é estabelecida. Outra fala desse entrevistado complementa essa observação:

Uma empresa que alterava sua estratégia de remuneração variável com certa frequência e acabava fazendo alterações lesivas nos contratos de trabalho. Esse caso surgiu quando identificamos que um empregado se queixou porque a empresa teria diminuído o seu salário. Quando fomos apurar o caso, identificamos outras alterações lesivas anteriores [ ...]. A remuneração era tão confusa e mudava tanto que o empregado não entendia o seu salário. Isso, por si só já representa risco, porque pode motivar o empregado a entrar na justiça. Mas acabamos por orientar a empresa sobre questões básicas para tornar a remuneração variável dela mais eficaz e sem riscos. (CSI - consultor)

O Feedback é também uma prática incorporada na Terceirizada. A partir do retorno que recebe da Cimenteira, a Terceirizada passa informações e orienta o seu pessoal, buscando reunir os empregados sempre que necessário. Os trechos a seguir mostram alguns relatos:

Direto eles reúnem a turma e passam tudo (TER8 - operacional).

Fala como que a gente tem que executar o serviço. Corrige, fala de segurança. Tem muita reunião e eles sempre tão falando de alguma coisa. Tipo saúde também. Fala de como a gente tem que fazer tudo aqui. Às vezes, eles recebem alguma reclamação da [Cimenteira], aí eles conversam com a gente (TER7 operacional).

Os resultados apresentados corroboram achados do estudo de Fernandes e Carvalho (2005a). Essa pesquisa identificou que, para enfrentar o desafio da qualificação dos trabalhadores de 
empresas terceiras, as contratantes têm investido na definição de critérios, políticas e regras para orientarem a gestão do contrato de terceiros. "Essa prática complementa-se com as seguintes: seleção dos terceirizados, contratação e negociação dos objetivos e metas, acompanhamento e avaliação do desempenho." (Fernandes \& Carvalho, 2005a). Esses autores também identificaram que a integração dos terceiros aos processos de treinamento e desenvolvimento da Contratante, a supervisão e o feedback são práticas utilizadas que visam garantir a melhoria dos serviços.

O estudo de Saraiva e Mercês (2013) aponta resultados que também podem ser confrontados com esta pesquisa. O trabalho desses autores mostra que a empresa contratante treina os empregados de uma contratada. A justificativa dada refere-se ao fato de que "a empresa contratante tem um domínio tecnológico de destaque no mercado", logo, o treinamento oferecido garantiria a execução de acordo com padrões estabelecidos. (Saraiva \& Mercês, 2013, p. 15). Essa é uma das justificativas da Cimenteira para os treinamentos que oferece aos empregados de suas contratadas.

\subsection{Motivos e Resultados: Por que Exercer Atuação sobre as Práticas da Terceirizada?}

Entre os motivos que levam a Cimenteira a atuar sobre as práticas de gestão de pessoas de suas contratadas encontra-se a busca pelo alcance do nível de excelência pretendido. Para tanto, reforça-se a necessidade de adesão das terceiras ao modelo de gestão:

Porque a tomadora de serviço precisa, necessariamente - para que ela seja excelente - ter como representante, como empresas aqui dentro, o modelo de gestão na veia aplicado a $100 \%$ dos profissionais. E não tem outro caminho de eu atingir $100 \%$ dos profissionais, se eu não envolver os terceiros. [ ...] Na hora que eu for fazer uma avaliação na minha organização, se o meu terceiro não tem a preocupação com o tema, está me dizendo diretamente que eu tenho um problema. E se ele está dentro da minha casa, o problema é meu (CTE1 - gestor).

Para os representantes da Cimenteira, o alcance dos objetivos estratégicos que se relacionam à qualidade, produtividade e segurança do trabalho passa, necessariamente, pelo envolvimento dos empregados da Contratada, o que é reforçado na literatura por Cardoso e Marras (2010). Segundo esses autores, o envolvimento da contratante nas práticas de gestão de pessoas das suas contratadas é determinante na perspectiva evolutiva das empresas dentro do cenário atual.

Também é possível verificar que a Cimenteira se mostra ciente de sua responsabilidade quanto aos empregados das contratadas que atuam em seu ambiente de produção. Não acompanhar as terceiras quanto ao cumprimento das obrigações legais, por exemplo, pode significar problemas para a Contratante. A fala a seguir confirma essa observação: "Isso já é uma política interna [ .... . A empresa entende que, quando uma empresa adentra a fábrica, ela é co-responsável por ela. Todos os requisitos, civis ou trabalhistas, ela é co-responsável por isso. Então [...] nós temos que preocupar com nossos terceiros." (CTE2 - gestor).

A atuação da Cimenteira pode também ser entendida a partir de um dos aspectos discutidos na literatura, que diz respeito à dificuldade de se encontrar empresas parceiras qualificadas para assumirem as atividades terceirizadas, significando um grande entrave do processo produtivo (Borges \& Druck, 1993; Fernandes \& Carvalho, 2005a, b; Leite \& Posthuma, 1996; Magalhães et al., 2010). Nesse sentido, é possível entender o fato de a Cimenteira despender esforços na busca de ajustamento da Terceirizada às suas necessidades. Um exemplo encontra-se nas orientações quanto a treinamento e desenvolvimento dos terceiros.

Para os representantes da Cimenteira, a sua atuação contribui para a formação de um quadro de terceirizados alinhados aos seus objetivos e, com isso, dá oportunidade para que, em caso de necessidade, um empregado de empresa terceirizada passe a integrar o seu quadro funcional. Sob essa perspectiva, é mitigada no contexto estudado a desigualdade de oportunidades de treinamento e desenvolvimento existente entre os empregados das contratantes e os trabalhadores das contratadas, configurando a qualificação profissional como um importante fator de definição da empregabilidade do trabalhador terceiro, conforme apontam Magalhães et al. (2010). Nota-se que as práticas e exigências da Cimenteira no que se refere à capacitação das pessoas são aplicadas com equilíbrio sobre empregados próprios e terceiros. A possibilidade de contratação de empregados terceiros pela Cimenteira alinha-se ao ideal de fortalecimento da empregabilidade do trabalhador terceirizado. Além disso, corroborando conclusões de Saraiva e Mercês (2013), a Cimenteira entende que a qualificação dos terceiros tem influência positiva na qualidade dos serviços realizados. 
No que tange às empresas contratadas, os entrevistados da Terceirizada reconhecem que a atuação da Cimenteira sobre suas práticas de gestão de pessoas tem reflexos sobre os seus processos e negócios e que se estendem ao âmbito pessoal do trabalhador, especialmente quanto à segurança no trabalho. Essa percepção alcança o nível operacional da Terceirizada.

De acordo com um entrevistado, a Cimenteira busca mostrar às contratadas os benefícios advindos de seu engajamento no modelo de gestão:

Quando eu consigo mostrar para essa empresa o valor que isso pode trazer para ela de forma positiva, e o quanto isso vai transformar o seu corpo de gestão e o seu corpo operacional no sentido de envolvê-los, e que isso pode, com certeza absoluta, trazer ganhos até juridicamente para ele, ou ganhos realmente de capital aqui dentro (CTE1 - gestor).

Embora os benefícios sejam percebidos, a relação Cimenteira-Terceirizada não deixa de ser permeada por conflitos diante da necessidade de adesão da segunda empresa às orientações da primeira. Isso pode ser atestado pelos entrevistados da Terceirizada e também pelo Consultor. Foram apontadas dificuldades na assimilação das orientações repassadas pela Cimenteira, gerando conflitos diretamente com os empregados da Terceirizada.

Tem muita coisa boa que a gente acaba aprendendo. E tem muita coisa que a gente vê que a nossa empresa fica até diferenciada em relação a outros clientes. Mas é muito difícil às vezes, porque eles exigem muito. [...] No fim posso dizer que vale a pena, que é positivo. Os empregados têm um pouco de dificuldade, principalmente em relação à segurança. Mas eles sabem que é pro bem deles e a gente reforça isso sempre (TER1 - gestor).

\section{Conforme colocado pela Consultoria:}

No começo é difícil pra muitas delas. Só aquelas que já são muito organizadas é que se adaptam imediatamente ao processo. As outras exigem mais treinamento e um empenho maior da nossa equipe para orientá-las. Mas com o tempo a grande maioria começa a sentir os benefícios desse trabalho e se sentem mais seguras. Quando elas percebem que também estão ganhando com isso, tudo flui mais naturalmente, sem muitos gargalos. (CS1 - Consultor)

A incorporação do modelo de gestão da Cimenteira, pela Terceirizada, corrobora as conclusões de Rachid et al. (2001). Sem ignorar as dificuldades do relacionamento entre as empresas no contexto da terceirização, esses autores concluíram que a ligação das pequenas e médias empresas fornecedoras com as grandes empresas clientes resulta num processo de qualificação dos fornecedores que passam a ter acesso a informações sobre as práticas mais atuais de gestão.

Por fim, destaca-se que as diversas oportunidades de transferência de conteúdo técnico entre as empresas estudadas, por meio de treinamentos, fóruns, comitês, reuniões, entre outros, acabam por tratar da ameaça relacionada à falta de qualificação dos fornecedores.

\section{Considerações Finais}

Este estudo, que teve como objetivo compreender como o relacionamento que se estabelece entre contratante e contratada afeta as práticas de gestão de pessoas da empresa terceirizada constatou que existe um processo intencional, planejado e consolidado de atuação da empresa contratante (Cimenteira) sobre a empresa Terceirizada. Ressalta-se, no entanto, que essa não é uma especificidade apenas da relação entre as duas empresas investigadas neste estudo. Conforme evidenciaram os entrevistados na Contratante e também na Consultoria, tal processo se dá pela busca de adesão das terceiras ao modelo de gestão da Cimenteira.

Destaca-se que nesse processo encontra-se envolvida uma empresa de Consultoria que presta serviços à Cimenteira e que exerce importante papel na mediação da relação entre as duas empresas investigadas: Cimenteira e Terceirizada. Tal Consultoria é responsável pela definição do modelo padrão ao qual devem aderir as empresas terceiras, presta orientação sobre esses padrões e monitora as terceirizadas no que se refere ao atendimento das regras estabelecidas.

Assim, verifica-se que a atuação da Cimenteira sobre uma contratada surge no nascimento da relação contratual e prossegue com as exigências e convívio cotidianos. O contrato firmado entre as empresas parte, em regra, do modelo padrão da Cimenteira, no qual estão contempladas exigências relacionadas à regularidade trabalhista e fiscal da Terceirizada, à obediência a normas de segurança 
do trabalho, além de cláusulas genéricas assecuratórias de patamares mínimos de qualidade. Assim, no dia a dia, a Contratante envolve os trabalhadores terceirizados, juntamente com seus próprios empregados, em diversas atividades que são ditadas por esse modelo de gestão, tais como reuniões, fóruns, comitês de área e programas de treinamento e desenvolvimento. Busca-se, dessa maneira, criar um ambiente onde se divulgam muitas informações sobre as questões de interesse da Cimenteira.

Os documentos analisados neste estudo, obtidos por intermédio da empresa de Consultoria, revelaram elementos de gestão de pessoas orientados pela Cimenteira. Exigências quanto à qualidade e produtividade, em especial, conduzem essa empresa a um processo de orientaçãomonitoramento dos terceiros que tem implicações sobre as práticas relacionadas a recrutamento e seleção, treinamento e desenvolvimento, SSMA, feedback e rotinas trabalhistas nas empresas terceirizadas.

A necessidade de se estabelecer um ambiente produtivo homogêneo e eficaz, mesmo com a multiplicidade de vínculos contratuais, representa uma das motivações da Cimenteira para atuar sobre as práticas de gestão de pessoas das terceiras. Associa-se a esse fator, a necessidade de alinhamento dos empregados da Terceirizada aos valores da Cimenteira. Dessa forma, a definição de padrões que configuram o chamado modelo de gestão e a sua adesão por todos os participantes do processo de produção é vista pela Cimenteira como uma condição para o alcance dos objetivos do seu negócio.

Para os envolvidos, a Contratante exerce uma atuação benéfica sobre a Terceirizada. As dificuldades iniciais que surgem a partir da busca pelo atendimento aos padrões esperados tendem a ser superadas e a Contratada adere ao modelo de gestão, que acaba sendo percebido como benéfico, contribuindo para a organização e a atualização de suas práticas de gestão de pessoas.

Dessa forma, entende-se que o esforço no sentido de envolver as contratadas em um contexto de regularidade, qualidade e produtividade orientando, entre outras, as suas práticas de gestão de pessoas aproxima o tipo de terceirização da Cimenteira daquele apontado por Druck (1999), no qual a terceirização é justificada pela busca de maior produtividade, qualidade e competitividade. Além disso, o ambiente estudado mostrou resultados que se alinham àqueles apresentados por Druck (1999), Gitahy (1994) e Ruas et al. (1994). Segundo esses autores, a relação estabelecida entre empresas contratantes e sua contratadas pode ser exitosa no sentido de possibilitar desenvolvimento e aprimoramento dos serviços prestados e dos produtos ofertados, além de uma gestão mais eficiente da mão de obra. Resultados percebidos como positivos pela Contratante e pela Terceirizada corroboram também os estudos de Magalhães et al. (2010) e de Lourenço et al. (2010).

Não obstante, deve-se ter em conta que a relação estabelecida entre Contratante-Terceirizada é também representada por dificuldades e conflitos que se apresentam na medida em que a Contratada precisa adequar os seus processos aos termos colocados pelo modelo de gestão. Há casos em que os conflitos ocorrem diretamente entre Contratante e empregados da Terceirizada, que se encontram atuando dentro das instalações da primeira.

Isso posto, alguns aspectos despertam para a possibilidade de realização de pesquisas futuras que busquem avaliar a relação contratante-contratada. Se, de um lado, os benefícios são aparentes para ambas as partes investigadas neste estudo, de outro lado, não se pode desconsiderar que a Terceira possa ter dificuldades diante da necessidade de manter esforços pouco condizentes com suas reais capacidades. Além disso, recomendam-se trabalhos que sigam a trilha de investigação da presente pesquisa, ampliando a discussão sob a ótica da parceria e das implicações de uma política de ganha-ganha sobre as práticas de gestão de pessoas das contratadas.

Por fim, destacam-se limitações do estudo, que se restringiu a investigar uma empresa contratada, não dando voz, portanto, a outras que também mantêm relações com a Cimenteira. Destaca-se, contudo, a sua contribuição. A literatura é vasta quando o tema terceirização é tratado sob a ótica da precarização das condições de trabalho, porém estudos que investigam o relacionamento contratante-contratada sob a ótica das implicações geradas sobre as práticas de gestão de pessoas das empresas terceiras são, ainda, incipientes.

\section{Notas}

1- Agradecemos aos avaliadores pelas significativas recomendações que contribuíram com a revisão do artigo. 
2- Agradecemos à FAPEMIG e ao CNPq pelo apoio.

\section{Referências}

Almeida, M. C., \& Silva, R. A. R. (1999). Estratégias de terceirização: um estudo em grandes empresas mineiras. Anais do Encontro Nacional da Associação Nacional de Pós-graduação e Pesquisa em Administração, Foz do Iguaçu, PR, Brasil, 23.

Barbosa, A. M. S. (2010). A naturalização da identidade social precarizada na indústria do alumínio primário paraense. Sociologias, 12(23), 268-303.

Bardin, L. (2011). Análise de conteúdo. Brasil: Edições 70.

Bitencourt, C. C. (Org.). (2010). Gestão contemporânea de pessoas. Porto Alegre: Bookman.

Borges, A., \& Druck, M. G. (1993). Crise global, terceirização e a exclusão do mundo do trabalho. Cadernos CRH, 19, 22-45.

Cardoso, M. A. F., \& Marras, J. P. (2010). Gestão integrada de pessoas nas alianças corporativas: desenvolvendo valor nos canais de distribuição. Anais dos Seminários em Administração, São Paulo, SP, Brasil, 13.

Carvalho, A. M., Neto. (2001). Relações de trabalho e negociação coletiva na virada do milênio: um estudo em quatro setores dinâmicos da economia. Belo Horizonte: Vozes.

Collis, J., \& Hussey, R. (2005). Pesquisa em Administração. Porto Alegre: Bookman.

Cruz, M. V. G., Sarsur, A. M., \& Amorim, W. A. C. (2012, outubro). Gestão de competências nas relações de trabalho: o que pensam os sindicalistas? Revista de Administração Contemporânea, 16(5), 705-722.

CutcherGershenfeld, J., Kochan, T., Ferguson, J.-P., \& Barrett, B. (2007). Collective bargaining in the twenty-first century: a negotiations institution at risk. Negotiation Journal, 23(3), 249-265.

Dedecca, C. S. (1996). Racionalização econômica e heterogeneidade nas relações e nos mercados. In A. L. Santos, C. A. B. Oliveira, \& J. Mattoso (Orgs.). Crise e trabalho no Brasil: modernidade ou volta ao passado? São Paulo: Scritta.

Druck, M. G. (1999). Terceirização: (des)fordizando a fábrica - um estudo do complexo petroquímico. Salvador: Bahia: Boitempo.

Druck, M. G. (2011). Trabalho, precarização e resistências: novos e velhos desafios? Cadernos CRH [ Edição Especial], 24, 37-57.

Faria, A. (1994). Terceirização: um desafio para o movimento sindical. In: H. S. Martins, \& J. R. Ramalho. (Orgs.). Terceirização: diversidade e negociação no mundo do trabalho. São Paulo: Hucitec - CEDI/NETS, 41-61.

Fernandes, M. E R. (2003). Gestão dos múltiplos vínculos de trabalho: um estudo sobre a visão dos dirigentes das maiores empresas operando no Brasil (Dissertação mestrado). Pontifícia Universidade Católica de Minas Gerais, Belo Horizonte, MG, Brasil.

Fernandes, M. E. R., \& Carvalho, A. M., Neto. (2005a) As práticas gerenciais frente aos principais desafios apontados pelas maiores empresas brasileiras na gestão de terceirizados. Anais do Encontro Nacional da Associação Nacional de Pós-Graduação e Pesquisa em Administração, Brasília, DF, Brasil, 29.

Fernandes, M. E. R., \& Carvalho, A. M., Neto. (2005b). Gestão dos múltiplos vínculos contratuais nas grandes empresas brasileiras, Revista de Administração de Empresas [ Edição Especial], 45, 48-59.

Figueiredo, M., Alvarez, D., Athayde, M., Suarez, J. D., \& Pereira, R. (2007). Reestruturação produtiva, terceirização e relações de trabalho na indústria petrolífera offshore da Bacia de Campos (RJ). Gestão da Produção, 14(1), 55-68.

Flick, U. (2004). Uma introdução à entrevista qualitativa. Porto Alegre: Bookman.

Gaskell, G. (2002). Entrevistas individuais e grupais. In M. W. BAUER, \& G. GASKELL (Orgs.). Pesquisa qualitativa com texto, imagem e som: um manual prático ( $2 \mathrm{a}$ ed.). Petrópolis: Vozes. 
Gitahy, L. (1994). Inovação tecnológica, relações interfirmas e mercado de trabalho. In L. Gitahy (Org.). Reestructuración productiva, trabajo y educación en América Latina (Lecturas de educación y trabajo, n. 3). Campinas: IG-UNICAMP. Buenos Aires: RED CIID-CENEP.

Guimarães, S., \& Carvalho, A. M., Neto. (2006). O futuro dos sindicatos: estudo sobre sindicatos de telecomunicações no Brasil. Cadernos do CRH (UFBA), 19(47), 277-291.

Hall, L. (2000, july). Outsourcing, contracting-out and labour hire: implications for human resources development in Australian organizations. Asia Pacific Journal of Human Resources, 38, 23-41.

Hirata, H. (2011). Tendências recentes da precarização social e do trabalho: Brasil, França, Japão. Cadernos CRH [ Edição Especial], 24, 37-57.

Izquierdo, C., \& Cillán, J. (2004). The interaction of dependence and trust in long-term industrial relationships. European Journal of Marketing, 38(8), 974-994.

Kochan, T. A. (1997). Rebalancing the role of human resources. Human Resource Management, $36(1), 121-126$.

Kochan, T. A. (2006). Taking the high road. Sloan Management Review, 47(4), 16-19.

Kolko, J. (1988). Restructuring the world economy. New York: Pantheon.

Lacombe, B. M. B., \& Tonelli, M. J. (2001, maio-agosto). O discurso e a prática: o que dizem os especialistas e o que nos mostram as práticas das empresas sobre os modelos de gestão de recursos humanos. Revista de Administração Contemporânea, 5(2), 157-174.

Leite, M., \& Posthuma, A. (1996). Reestruturação produtiva e qualificação: reflexões sobre a experiência brasileira. São Paulo em Perspectiva, 10(1), 63-76.

Lima, J. C. (2010). A terceirização e os trabalhadores: revisitando algumas questões. Cadernos de Psicologia Social do Trabalho, 13, 17-26.

Lisboa, A. M., Carvalho, A., Neto, Nunes, S. C, \& Lima, G. S. (2011, janeiro-julho). Desafios da gestão de pessoas em empresas do segmento logístico de distribuição de bebidas. Revista Gestão \& Tecnologia, 11(1), 1-11.

Lourenço, S. C. C., Villela, L. E., \& Freitas, J. A. de S. B. (2010). A percepção de trabalhadores terceirizados sobre as práticas de gestão de pessoas nas empresas offshore da rede petro bacia de campos. Contextus - Revista Contemporânea de Economia e Gestão, 8(1), 45-56.

Ludke, M., \& André, M.E.D.A. (1986). Pesquisa em educação: abordagens qualitativas. São Paulo, Editora Pedagógica e Universitária.

Magalhães, Y. T. (2008). Gestão de terceirizados: múltiplos desafios (Dissertação de mestrado). Pontifícia Universidade Católica de Minas Gerais, Belo Horizonte, MG, Brasil.

Magalhães, Y. T., Carvalho, A., Neto, \& Gonçalves, P. P. B. (2010, janeiro-abril). Os múltiplos desafios da gestão de terceirizados: a experiência dos gestores de contratos. Revista de Ciências da Administração, 12(26), 116-143.

Magalhães, Y. T., Carvalho, A., Neto, \& Saraiva, L. A. S. (2011, abril-junho). Práticas gerenciais relacionadas à qualificação de trabalhadores terceirizados: um estudo de caso no setor de mineração. Organizações \& Sociedade, 18(57), 227-244.

Marchalek, C. R. L., Rebelato, M. G., \& Rodrigues, I. C. (2007, maio-agosto). Estudo sobre as diferenças de percepção dos fatores relacionais entre empresa e terceirizado. Produção, 17(2), 286301.

Olsen, K. M., \& Kalleberg, A. L. (2004, junho). Non-Standard work in two different employment regimes: Norway and United States. Work, employment and society, 18(2), 321-348.

Pochmann, M. (2011). Perspectivas das relações de trabalho no brasil no começo do século 21 . In M. C. Cacciamali, R. Ribeiro, \& J. Macambira (Orgs.). Século XXI: transformações e continuidades nas relações de trabalho (Vol. 1). Fortaleza: Instituto de Desenvolvimento do Trabalho, Banco do Nordeste, 127-144.

Posthuma, A. (1990). Japanese production techniques in Brazilian automobile components firms: a best practice model or basis for adaptation. Conference Organization and Control of the Labour Process, Birmingham. Birmingham: Aston University. 
Prahalad, C. K., \& Hamel, G. (1990, may-june). The core competence of the corporation. Harvard Business Review, 68(3), 79-93.

Purcell, K., \& Purcell, J. (1998). In-sourcing, outsourcing, and the growth of contingent labour as evidence of flexible employment strategies. European journal of work and organizational psychology, $7(1), 39-59$.

Queiroz, C. A. R. S. (1998). Manual de Terceirização (9a ed). São Paulo: STS.

Rachid, A., Bresciani, E., \& Gitahy, L. (2001, dezembro). Relações entre grandes e pequenas empresas de autopeças e a difusão de práticas de gestão da produção. Gestão \& Produção, 8(3), 319-333.

Rezende, W. (1997, outubro-dezembro). Terceirização: a integração acabou? Revista de Administração de Empresas, 37(4), 6-15.

Ruas, R., Gitahy, L., Rabelo, F., \& Antunes, E. D. D. (1994). Inter-firm relations, collective efficiency and employement in two brasilian clusters. International Labour Office Working Paper, (242).

Ryngelblum, A. L. (1999). Relacionamento entre desiguais: o papel da terceirização na reestruturação das grandes empresas. Anais do Encontro Nacional da Associação Nacional de PósGraduação e Pesquisa em Administração, Foz do Iguaçu, PR, Brasil, 23.

Sabel, C. E., \& Zeitlin, J. (1985, august). Historical alternatives to mass production: politics, markets and technology in nineteenth-century industrialization. Past and Present, 108, 133- 175.

Salerno, M. S. (2004, janeiro-abril). Da rotinização à flexibilização: ensaio sobre o pensamento crítico brasileiro de organização do trabalho. Gestão \& Produção, 11 (1), 21-32.

Saraiva, L. A. S., \& Mercês, R. E. D. (2013). Terceirização na gestão da manutenção: estudo de caso de uma mineradora. Revista de Administração da Unimep, 11(1), 1-24.

Saraiva, L. A. S., Ferreira, J. A., \& Coimbra, K. E. R. (2012). Relações de trabalho em empresas terceirizadas sob a ótica dos trabalhadores: um estudo no setor de mineração. RGO - Revista Gestão Organizacional, 5(2), 134-148.

Sarsur, A. M., Cançado, V. L., Fernandes, M. E. R., \& Steuer, R. S. (2002, agosto). Repensando as relações de trabalho: novos desafios frente aos múltiplos vínculos de trabalho. Caderno de Idéias Cl0212, Fundação Dom Cabral.

Silva, G. A. V., Cançado, V. L., Fernandes, M. E. R., \& Steuer, R. S. (2001). Desafio na gestão de pessoas em ambientes com diferentes tipos de vínculos de trabalho. Anais do Encontro Nacional da Associação Nacional de Pós-Graduação e Pesquisa em Administração, Campinas, SP, Brasil, 25.

Uderman, S. (2007, julho-setembro). Transformações produtivas e novos padrões organizacionais da Indústria: uma tentativa de sistematização do debate. Organizações \& Sociedade, 14(42), 15-27. 